about their views on helpful aspects of these programs. Our study sought to describe the active components of a work rehabilitation program based on the best scientific evidence, from the participants' perspective.

Methods This study is the qualitative part of a broader research project aimed at the developmental evaluation of the program using a mixed methods approach over two years. We conducted semi-structured interviews of 26 participants after program completion. The questions concerned the program components they considered beneficial and their reasons. The interviews were conducted by telephone, recorded and analysed using thematic analysis principles. Converging themes were identified and classified by component type.

Result The active components identified concerned the interventions' group format, activities, and occupational therapists (OTs). Participants saw three benefits to the group format: it offsets the feelings of isolation and shame associated with mental disorders; allows them to adjust their view of their work disability and means for reducing it; and reactivates their social interaction skills. The activities seen as most beneficial concerned training on techniques to better cope with work and daily life (e.g. mindfulness meditation). OTs were seen as having three main functions: relaying information to physicians and other stakeholders; coaching (supporting integration of the techniques, giving meaning to the experience, pointing to external resources); and ensuring the therapeutic environment of the group interventions.

Discussion Our study results provide valuable insights into components that should be priorities if we are to ensure that work rehabilitation programs meet this population's needs. While additional work is required, current results suggest that a group format is an important intervention component for workers with CMDs.

\section{PRACTICAL TYPES OF GOOD PRACTICES FOR WORKERS WITH INTELLECTUAL DISABILITIES IN JAPANESE INDUSTRIAL WORKPLACES}

Y Sano*, N Okuta, S Saito, K Sakai. The Ohara Memorial Institute for Science of Labour, Tokyo, Japan

\subsection{6/oemed-2018-ICOHabstracts.1536}

Introduction A clear trend is seen in Japan in advancing the employment of workers with disabilities. The new amendments in 'the Act on Employment Promotion etc. of Persons with Disabilities' suggest companies to increase the rate of employment for workers with disabilities. Due to lack of knowledge and experiences, the retention rate of workers with intellectual disabilities remains low. It is necessary to extend case-based approaches for these workers relying on ongoing good practices.

Methods From the reports at the Japan Organisation for Employment of the Elderly, Persons with Disabilities and Job Seekers, 128 workplace-level good practices for supporting workers with intellectual disabilities were identified. The approaches taken by these practices were categorised into five technical areas by a team of well-experienced occupational health practitioners. We analysed common features and mutual relationships of these approaches.

Results While the size and industry of the corresponding companies were different, several key trends could be extracted from these good practices. Of 128 examples of support for workers with intellectual disabilities, 51 were about 'work methods', 28 about 'employment adjustment', 22 about 'securing work-life balance', 13 about 'improving communication' and 10 about 'workplace environment'. It was striking that the workplaces implemented these practices on plural areas. Three key trends could be thus extracted; (a) implementation of the practices covering multiple technical areas, (b) combining work methods and employment adjustment as essential areas for supporting workers with intellectual disabilities, and (c) Improving communication and workplace environment as areas further taken in advancing the support of these workers. Conclusion The extracted three key trends in good practices for workers with intellectual disabilities suggest the importance of comprehensive support measures addressing the multifaceted measures. 'Work methods' and 'employment adjustment' are essential areas for this support, and 'improving communication' and 'workplace environment' are applicable for extending the support.

\section{SUCCESS FACTORS FOR REHABILITATION AND RETURN TO WORK SYSTEMS IN THE CONTEXT OF AN AGEING WORKFORCE}

Timothy Tregenza*, Sarah Copsey. European Agency for Safety and Health at Work (EUOSHA), Bilbao, Spain

\subsection{6/oemed-2018-ICOHabstracts. 1537}

Introduction EU-OSHA initiated the Safer and healthier work at any age project in 2013 to investigate ways of improving health and safety at work considering the challenges of an ageing workforce.

Methods The project considered rehabilitation and return to work with a research review, an analysis report and nine case studies on rehabilitation/RTW programmes.

Results The analyses identified different approaches across the State systems examined, prerequisites for a successful system, and factors for a successful rehabilitation and RTW system. The research review examined prerequisites for a successful rehabilitation and return to work system. In general:

- Evidence points to the beneficial effects of work on health and well-being,

- Interventions that contain a workplace component appear to be more effective, and

- The sooner an intervention takes place, the more effective it is likely to be.

The analysis report identified common elements that contribute to effective return to work and rehabilitation systems at national and workplace levels. These included:

- A legal framework that covers all aspects of the process;

- Integration of the inclusive RTW system into a comprehensive policy framework;

- Good coordination across relevant policy areas;

- Successful interventions that are tailored to the worker;

- The use of incentive based systems without binding instruments; and

- Provision of financial and technical support

Discussion This is the first European overview on this topic. It highlights that governments should move towards a system that encourages an integrated system that focuses on workers' capabilities rather than their disabilities. 